\title{
Spotlight on ertugliflozin and its potential in the treatment of type 2 diabetes: evidence to date
}

This article was published in the following Dove Press journal:

Drug Design, Development and Therapy

3 October 2017

Number of times this article has been viewed

\section{Francesca Cinti* \\ Simona Moffa* \\ Flavia Impronta* \\ Chiara MA Cefalo \\ Vinsin A Sun \\ Gian Pio Sorice \\ Teresa Mezza \\ Andrea Giaccari}

Center for Endocrine and Metabolic Diseases, Fondazione Policlinico Universitario A Gemelli, Università

Cattolica del Sacro Cuore, Rome, Italy

*These authors contributed equally to this work
Correspondence: Andrea Giaccari Center for Endocrine and Metabolic Diseases, Fondazione Policlinico Universitario A Gemelli, Università Cattolica del Sacro Cuore, Largo A Gemelli 8, 00168 Rome, Italy

Tel +390630I5 7094

Email andrea.giaccari@unicatt.it

\begin{abstract}
Sodium-glucose cotransporter 2 (SGLT2) inhibitors are the latest therapeutic strategy in the treatment of type 2 diabetes mellitus (T2DM). Using an insulin-independent mechanism (glycosuria), they reduce glucose toxicity and improve insulin sensitivity and $\beta$-cell function. The promising results obtained in clinical trials show that SGLT2 significantly improves glycemic control and provides greater cardiovascular protection, combined with a reduction in body weight and blood pressure (BP). This review focuses on ertugliflozin, a new, highly selective, and reversible SGLT2 inhibitor. Clinical trials published to date show that ertugliflozin, both as a monotherapy and as an add-on to oral antidiabetic agents, is safe and effective in reducing glycosylated hemoglobin ( $\mathrm{HbA1c}$ ), body weight, and BP in T2DM patients.
\end{abstract}

Keywords: antidiabetic drugs, glycosylated hemoglobin, glycemic control, sodium-glucose cotransporter 2 inhibitors, precision medicine, type 1 diabetes mellitus, type 2 diabetes mellitus, weight reduction

\section{Introduction}

The role of kidneys in maintaining glucose homeostasis is well known, but they have only recently become a therapeutic target in patients with type 2 diabetes mellitus (T2DM). Kidneys transfer all plasma glucose into urine within the nephron but subsequently completely reabsorb the filtered glucose through two types of sodium-glucose cotransporters (SGLTs), ${ }^{1}$ unless plasma glucose reaches a threshold of $\sim 180 \mathrm{mg} / \mathrm{dL}$. Thus, under physiological conditions, no glucose is present in urine. When the concentration of plasma glucose exceeds this threshold, SGLTs become saturated and glucose in excess is excreted through urine (glycosuria), a typical sign of diabetes. ${ }^{2}$ Hyperglycemia increases the renal threshold for glycosuria, and the kidney itself contributes to the progression of hyperglycemia by increasing glucose reabsorption in response to an elevated threshold for glycosuria and by an increase in maximum glucose reabsorptive capacity. ${ }^{3}$

SGLTs belong to a large family of sodium-glucose cotransporters: the sodium/ glucose cotransport family SLC5. ${ }^{4}$ Two major SGLT isoforms have been described: SGLT2, which is highly expressed in the brush border of epithelial cells in S1 and S2 segments of proximal renal tubules, and SGLT1, expressed primarily in the small intestine, the S3 segment of the proximal renal tubule, and in the myocardium. ${ }^{5}$

In healthy humans, under normal physiological conditions, SGLT2 is responsible for $80 \%-90 \%$ of renal glucose reabsorption and SGLT1 for the remaining $10 \%-20 \%{ }^{6}$ These proteins carry glucose through the membranes of the proximal tubule epithelial cell in an active process that involves sodium transportation, facilitated by the sodium gradient between the tubule and the cell, which supports secondary active cotransport 
of glucose. Glucose then passively diffuses into the intercellular space, mainly via the GLUT2 (glucose transporter 2), a member of the GLUT protein family. ${ }^{7}$

Data from animal models of diabetes and from preclinical human studies suggest that hyperglycemia in T2DM is associated with a significantly increased expression of SGLT2 and GLUT2 proteins. ${ }^{8}$ However, a recent paper published by Ferrannini et al reports a reduction of SGLT2 expression in diabetic patients with preserved renal function, raising the possibility that a higher expression may be limited to diseased kidneys. ${ }^{9}$

Despite the latter controversy, SGLT2 has become a new successful therapeutic target for the treatment of diabetes. In fact, blocking SGLT2 via selective inhibitors increases the excretion of glucose from the body (via inhibition of renal glucose reabsorption), thereby reducing hyperglycemia in T2DM. Glycosuria induced by SGLT2 inhibitors (SGLT2is) provides relief from glucose toxicity, ${ }^{10,11}$ thus improving $\beta$-cell insulin secretion and insulin sensitivity in peripheral tissues, leading to a further reduction in plasma glucose concentration. ${ }^{12}$ Added benefits are a significant reduction in blood pressure (BP) ${ }^{13}$ and body weight, even though the latter is lower than expected considering the constant calorie loss through glycosuria $(200 \mathrm{kcal} /$ day for a daily loss of $50 \mathrm{~g}$ of glucose). ${ }^{14}$

SGLT2is (aka gliflozins) also seem to provide important cardioprotective benefits, although the mechanism is, intriguingly, still unknown. ${ }^{15,16}$ Treatment with gliflozins induces a switch in energy source, from glucose to fat, leading to two main metabolic consequences: a reduction in glucose oxidation and an increase in free fatty acid oxidation with the stimulation of ketogenesis. ${ }^{14}$ The latter process has given rise to the "Thrifty Substrate" hypothesis proposed by Ferrannini et al to provide a potential explanation for the clinically observed cardiovascular (CV) benefits. The selection of b-hydroxybutyrate instead of fatty acids by the heart may enhance the efficiency at the mitochondrial level and may be responsible for the improved myocardial performance. ${ }^{17}$ Lopaschuk and Verma, on the other hand, have proposed a contrasting hypothesis: gliflozins may inhibit myocardial ketone oxidation with a consequent reduction in Acetyl-CoA. This leads to a reduction of detrimental hyper-acetylation of mitochondrial enzymes and to increased pyruvate oxidation derived from glucose. These two actions might be responsible for an improvement in mitochondrial energy production and myocardial metabolism. ${ }^{18}$

Besides this controversy, two recent clinical trials with empagliflozin and canagliflozin (EMPAREG and
CANVAS, respectively), involving subjects with T2DM and high CV risk, have shown, to a different extent, a significant reduction in death from major adverse $\mathrm{CV}$ events (3-point MACE - Composite Endpoint of Major Adverse Cardiovascular Events: CV death, non-fatal myocardial infarction, or non-fatal stroke)..$^{15,16,19}$ An ongoing Phase III study (currently non-recruiting) will study the CV outcomes in T2DM participants with vascular disease following ertugliflozin treatment versus placebo (ClinicalTrials.gov NCT01986881).

Given this reduction in MACE events, SGLT2is are increasingly being used to treat T2DM. However, there is still a general consensus that metformin should be used as first-line therapy for T2DM, because in addition to lowering hepatic glucose production, it has a mild effect on peripheral resistance and could also be cardioprotective, especially in obese T2DM patients in primary prevention. ${ }^{20}$ SGLT2is are thus recommended as second- or third-line therapy for managing hyperglycemia in T2DM patients. ${ }^{21,22}$ This topic deserves a review of its own and therefore will not be discussed further in this article.

SGLT2is are also known to induce short- and long-term reduction in $\mathrm{BP} .{ }^{23} \mathrm{As}$ expected, considering their mechanism of action, SGLT2is are effective in reducing both systolic (SBP) and diastolic blood pressure (DBP), likely due to glucosedriven osmotic diuresis, as shown by increases in hematocrit and decreases in body weight. ${ }^{24}$ Osmotic diuresis leads to the excretion of glucose and water, resulting in increased urinary output ranging from $\sim 110$ to $470 \mathrm{~mL} /$ day. ${ }^{24}$

As indicated by Mosley et al, ${ }^{25}$ SGLTi treatment can lead to hypotension and dehydration in elderly T2DM patients (ie, 65 years and older). It is therefore critical to train these patients to recognize dehydration symptoms (eg, dizziness, lightheadedness, and fainting) and orthostatic hypotension and to prevent dehydration by drinking adequate amounts of fluids. ${ }^{26}$

Diuresis, however, accounts only for the short-term BP reduction induced by SGLT2is. Previous studies have observed that urine volume returns to pretreatment levels after $\sim 12$ weeks of treatment with SGLT2is, whereas BP reduction persists, ${ }^{27,28}$ implying that diuresis is not the only mechanism involved. Other possible mechanisms, accounting particularly for long-term BP reduction, include nephron remodeling, reduction in arterial stiffness, and loss of body weight. ${ }^{29}$ The renin-angiotensin system (RAS) plays a major role in the regulation of BP and fluid volume. Although the systemic RAS is important, the locally acting RAS, particularly that of the kidneys, is critical. There is a concern that 
Table I SGLT2/SGLTI selectivity of main SGLT inhibitors ${ }^{33-37}$

\begin{tabular}{llll}
\hline Molecule & $\begin{array}{l}\text { SGLT2 } \\
\text { (IC50 nM) }\end{array}$ & $\begin{array}{l}\text { SGLTI } \\
\text { (IC50 nM) }\end{array}$ & $\begin{array}{l}\text { SGLT2 selectivity } \\
\text { over SGLTI }\end{array}$ \\
\hline Empagliflozin & 3.1 & 8,300 & $\sim 2,500$-fold \\
Ertugliflozin & 0.87 & 1,960 & $\sim 2,000$-fold \\
Dapagliflozin & 1.2 & 1,400 & $\sim 1,200$-fold \\
Canagliflozin & 2.7 & 710 & $\sim 250$-fold \\
Sotagliflozin & 1.8 & 36 & $\sim 20$-fold \\
Phlorizin & 2,800 & 4,200 & $\sim 1.5$-fold \\
\hline
\end{tabular}

Abbreviations: IC50, half-maximal inhibitory concentration; SGLT, sodium-glucose cotransporter.

the sodium/volume loss induced by SGLT2is could activate the RAS, indeed Cherney et $\mathrm{al}^{30}$ have reported that total angiotensinogen excretion, a marker of local RAS activity in the kidney, ${ }^{31}$ significantly increases in type 1 diabetic patients (T1DM) treated with SGLT2is. A recent study, however, has shown that the total urinary angiotensinogen/creatinine ratio and intact angiotensinogen/creatinine ratio tended to decrease in T2DM patients treated with SGLT inhibitors. ${ }^{32}$

Several SGLT inhibitors have currently been approved in Europe and the USA (dapagliflozin, canagliflozin, and empagliflozin) while others are still under investigation (sotaglifozin and ertugliflozin). The main selectivity differences are summarized in Table $1 .^{33-37}$

This review focuses on the efficacy and safety of the highly selective and reversible SGLT2i ertugliflozin.

\section{Methods}

A systematic literature search was conducted using electronic databases, including PubMed and Web of Science. Different keywords were used to identify key papers related to preclinical and human studies on ertugliflozin, including "ertugliflozin" or "PF-04971729" or "SGLT2 inhibitors" or "type 2 diabetes mellitus."

We focused our selection, prioritizing randomized controlled clinical trials with ertugliflozin and other SGLT2is. We also focused on meta-analyses and systematic reviews. Reference lists of the principal articles considered were used to find additional relevant papers. No restrictions were adopted for other study characteristics, such as numbers of subjects enrolled, endpoints, and so on.

\section{Ertugliflozin: pharmacokinetics, metabolism, and excretion}

Ertugliflozin (PF-04971729) is a novel molecule belonging to a new class of SGLT2is incorporating a unique dioxa-bicyclo [3.2.1] octane (bridged ketal) ring system (Figure 1), which has demonstrated remarkable selectivity in vitro $(>2,000$-fold) for SGLT2 receptors over SGLT1

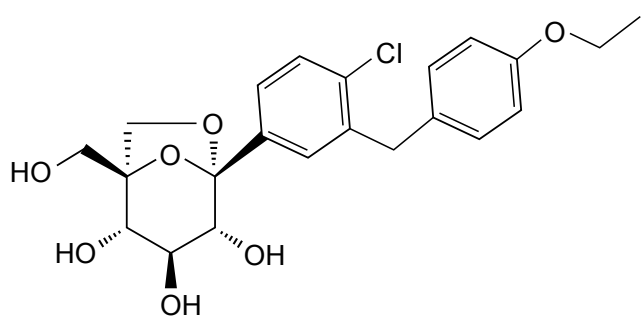

Figure I Molecular structure of ertugliflozin: (IS,2S,3S,4R,5S)-5-[4-Chloro-3(4-ethoxybenzyl)phenyl]-I-hydroxymethyl6,8-dioxabicyclo[3.2.I]octane-2,3,4-triol (PF-04971729).

and revealed a concentration-dependent glycosuria after oral administration in rats. ${ }^{33}$

An open-label Phase I study showed that plasma concentration peaks $\sim 1$ hour after administration of a single oral dose of $\left[{ }^{14} \mathrm{C}\right]$-Ertugliflozin $25 \mathrm{mg}$ in healthy male subjects, indicating rapid oral absorption. Systemic exposure was dose proportional over the dose range of $0.5-300 \mathrm{mg}$, while elimination half-life was about 17 hours, making once-a-day dosing possible. ${ }^{38}$

Furthermore, ertugliflozin was found to be highly bound to plasma protein ( $96 \%$ in rats and dogs, $94 \%$ in humans) and binding was independent of concentration in the various species. ${ }^{39}$

Its primary biotransformation pathway is glucuronidation, through UDP-glucuronosyltranferase isozyme IA9, which is involved in the formation of the two main ertugliflozin metabolites: ertugliflozin-4- $\beta$-O-glucuronide and ertugliflozin3- $\beta$-O-glucuronide (M4a and M4c). The oxidative metabolic pathway plays a lesser role, through cytochrome P450 (P450), to yield monohydroxylated metabolites (M1 and M3) and des-ethyl ertugliflozin (M2). Renal excretion of unchanged ertugliflozin is considered negligible, whereas almost half of the orally administered dose is recovered as urinary metabolites (Figure 2). ${ }^{40}$

Given the recent advent of fixed-dose combination drugs (FDCs), an ertugliflozin-sitagliptin FDC trial was conducted and has recently been completed. This open-label, randomized, three-period, single-dose, crossover study, in which 12 healthy adult subjects received ertugliflozin $15 \mathrm{mg}$, sitagliptin $100 \mathrm{mg}$ and ertugliflozin plus sitagliptin, showed that coadministration of ertugliflozin and sitagliptin had no effect on either ertugliflozin $\mathrm{AUC}_{\text {inf }}$ or $\mathrm{C}_{\text {max }}$; similarly, ertugliflozin did not affect sitagliptin $\mathrm{AUC}_{\text {inf }}$ or $\mathrm{C}_{\max }$. Analogous results were obtained with metformin. The absence of pharmacokinetic interaction demonstrates that ertugliflozin can be coadministered with both sitagliptin and metformin without dose adjustments. ${ }^{41}$ 
A

$$
\text { Metabolism }
$$

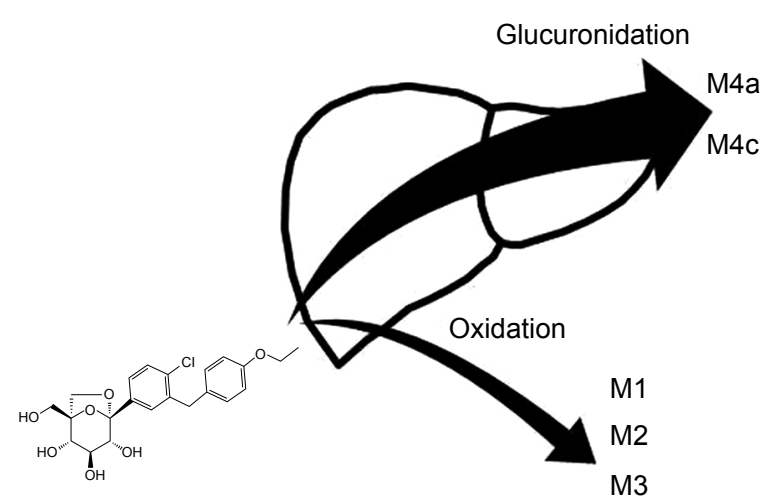

B

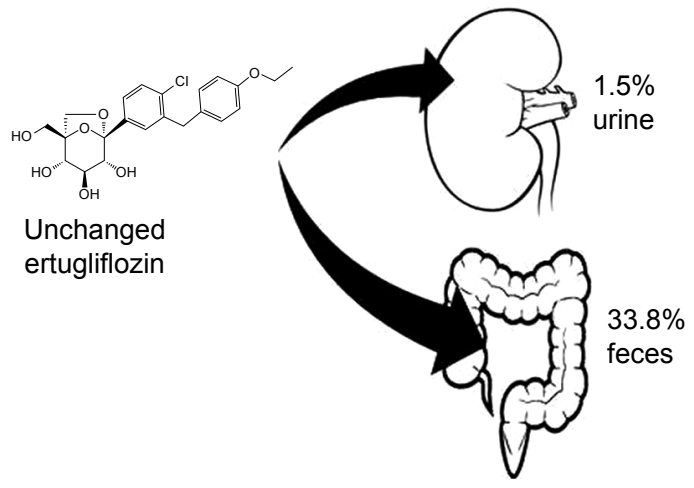

Figure 2 (A) Hepatic metabolism of ertugliflozin. Its primary biotransformation pathway is glucuronidation, through UDP-glucuronosyltranferase isozyme IA9, which is involved in the formation of the two main ertugliflozin metabolites: ertugliflozin-4- $\beta$-O-glucuronide and ertugliflozin-3- $\beta$-O-glucuronide (M4a and M4c). Oxidative metabolic pathway plays a lesser role, through cytochrome P450 (P450), to yield monohydroxylated metabolites (MI and M3) and des-ethyl ertugliflozin (M2). (B) Excretion of unchanged ertugliflozin.

As renal impairment is a common comorbidity in T2DM, the effect of renal impairment on pharmacokinetics and pharmacodynamics has been evaluated in T2DM subjects. A single oral dose of ertugliflozin $15 \mathrm{mg}$ was administered to normal subjects and to subjects with varying degrees of renal impairment. As expected, systemic exposure to ertugliflozin increased by $<2$-fold in subjects with renal impairment compared to subjects with normal renal function, and 24-hour urinary glucose excretion decreased with declining renal function, due to decreased filtered glucose load. Ertugliflozin is therefore well tolerated in subjects with normal renal function and in T2DM subjects with renal impairment. ${ }^{42}$

\section{Studies on ertugliflozin}

The efficacy and safety of ertugliflozin, as monotherapy and as add-on/combination therapy with other antidiabetic drugs in patients with diabetes mellitus, is currently being established through a series of Phase II and Phase III trials, the VERTIS Studies: eValuation of ERTugliflozin effIcacy and Safety. To date, there are six completed Phase III studies, whose main characteristics are illustrated in Table 2.

\section{Efficacy}

\section{Blood glucose control}

In a Phase II study, ertugliflozin was evaluated at doses ranging from 1 to $25 \mathrm{mg}(1,5,10,25 \mathrm{mg})$ once-daily, in patients with T2DM in treatment with stable doses of metformin, compared with sitagliptin $100 \mathrm{mg}$ and placebo; mean $\mathrm{HbA} 1 \mathrm{c}$ decreased from baseline to week 12 in all ertugliflozin groups (from $-0.45 \%$ to $-0.72 \%$ depending on the treatment group), compared with placebo. In particular, doses of more than $5 \mathrm{mg} /$ day yielded an effect on $\mathrm{HbA} 1 \mathrm{c}$ that was numerically

Table 2 Phase III completed clinical trials

\begin{tabular}{|c|c|c|c|c|c|c|c|c|}
\hline \multirow{2}{*}{$\begin{array}{l}\text { Study } \\
\text { VERTIS MONO }{ }^{44,45}\end{array}$} & \multirow{2}{*}{\begin{tabular}{|l|}
$\begin{array}{l}\text { No of } \\
\text { patients }\end{array}$ \\
461
\end{tabular}} & \multirow{2}{*}{\begin{tabular}{|l|}
$\begin{array}{l}\text { Duration } \\
\text { (weeks) }\end{array}$ \\
$26+26$
\end{tabular}} & \multirow{2}{*}{ 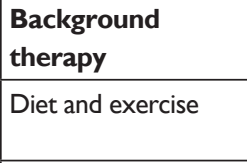 } & \multicolumn{5}{|l|}{ Arms } \\
\hline & & & & ERTU 5 mg & ERTU 15 mg & $\begin{array}{l}\text { Placebo (phase A)/ } \\
\text { metformin (phase B) }\end{array}$ & & \\
\hline VERTIS MET ${ }^{46}$ & 621 & $26+26$ & $\begin{array}{l}\text { Metformin } \\
\geq 1,500 \mathrm{mg} \text { die } \\
\end{array}$ & ERTU $5 \mathrm{mg}$ & ERTU $15 \mathrm{mg}$ & Placebo & & \\
\hline $\begin{array}{l}\text { VERTIS } \\
\text { FACTORIAL }{ }^{47,48}\end{array}$ & 1,233 & $26+26$ & $\begin{array}{l}\text { Metformin } \\
\geq 1,500 \mathrm{mg} \text { die }\end{array}$ & ERTU 5 mg & ERTU I5 mg & Sita 100 mg & $\begin{array}{l}\text { ERTU } 5 \mathrm{mg}+ \\
\text { SITA } 100 \mathrm{mg}\end{array}$ & $\begin{array}{l}\text { ERTU I5 mg + } \\
\text { SITA } 100 \mathrm{mg}\end{array}$ \\
\hline VERTIS SITA ${ }^{49}$ & 291 & 26 & Diet and exercise & $\begin{array}{l}\text { ERTU } 5 \mathrm{mg}+ \\
\text { SITA } 100 \mathrm{mg}\end{array}$ & $\begin{array}{l}\text { ERTU } 15 \mathrm{mg}+ \\
\text { SITA } 100 \mathrm{mg}\end{array}$ & Placebo & & \\
\hline VERTIS SITA2 $2^{50,51}$ & 463 & $26+26$ & $\begin{array}{l}\text { Metformin } \\
\geq 1,500 \mathrm{mg} \text { die }+ \\
\text { Sitagliptin } 100 \mathrm{mg} \text { die }\end{array}$ & ERTU $5 \mathrm{mg}$ & ERTU $15 \mathrm{mg}$ & Placebo & & \\
\hline VERTIS SU ${ }^{52}$ & 1,326 & 52 & $\begin{array}{l}\text { Metformin } \\
\geq 1,500 \mathrm{mg} \text { die }\end{array}$ & ERTU $5 \mathrm{mg}$ & ERTU $15 \mathrm{mg}$ & Titrated glimepiride & & \\
\hline
\end{tabular}

Abbreviations: ERTU, ertugliflozin; SITA, sitagliptin. 
similar to that obtained with sitagliptin $100 \mathrm{mg}$. A greater proportion of patients treated with ertugliflozin reached $\mathrm{HbA} 1 \mathrm{c}<7 \%$ at week 12 and a significant reduction from baseline in fasting plasma glucose (FPG) was also observed. ${ }^{43}$

The VERTIS MONO Phase III trial evaluated the efficacy and safety of ertugliflozin monotherapy in subjects with T2DM and inadequate glycemic control, despite diet and exercise (Table 2). Results from the placebo-controlled phase (phase A) of this study have been published recently. ${ }^{44}$ Change from baseline in HbAlc at week 26 showed a significantly greater decrease in the ertugliflozin $5 \mathrm{mg}(-0.99 \%$; $p<0.001)$ and $15 \mathrm{mg}(-1.16 \% ; p<0.001)$ groups, compared with placebo, which was more evident in subjects with baseline $\mathrm{HbA} 1 \mathrm{c}>8 \%$. At week 26, ertugliflozin 5 and $15 \mathrm{mg}$ also achieved a significantly greater reduction in the secondary endpoints, namely, FPG and 2-hour postprandial glucose, compared with placebo (Figure 3; Table S1). ${ }^{44}$

Data from the active, controlled 26-week follow-up phase were recently presented at the 77 th ADA scientific session. Patients previously treated with placebo had metformin added, but there were no formal comparisons for efficacy between placebo/metformin group and ertugliflozin group at week 52. There was a meaningful reduction in $\mathrm{HbA} 1 \mathrm{c}$ from baseline, in both ertugliflozin groups (Table S1), the same benefit was observed in FPG reduction (ertugliflozin $5 \mathrm{mg}-30.07 \mathrm{mg} / \mathrm{dL}$; ertugliflozin $15 \mathrm{mg}-37.55 \mathrm{mg} / \mathrm{dL}){ }^{45}$
Ertugliflozin efficacy has also been evaluated as add-on or combination therapy with sitagliptin and metformin. The VERTIS MET trial investigated the efficacy and safety of ertugliflozin, versus placebo, in patients with T2DM, inadequately controlled with metformin monotherapy ( $\geq 1,500 \mathrm{mg} /$ day $\geq 8$ weeks) (Table 2 ). At week 26 , both the ertugliflozin groups showed a significant decrease in $\mathrm{HbA} 1 \mathrm{c}$ and FPG from baseline. Specifically, ertugliflozin $5 \mathrm{mg}$, compared with placebo, caused a reduction in $\mathrm{HbA} 1 \mathrm{c}$ of $-0.7 \%$ $(p<0.001)$ and of $-26.69 \mathrm{mg} / \mathrm{dL}(p<0.001)$ in FPG, while ertugliflozin $15 \mathrm{mg}$ caused a reduction of $-0.88 \%(p<0.001)$ in $\mathrm{HbA} 1 \mathrm{c}$ and of $-38.25 \mathrm{mg} / \mathrm{dL}(p<0.001)$ in FPG (Figure 3; Table S1). ${ }^{46}$

The VERTIS FACTORIAL study investigated the efficacy and safety of coadministration of ertugliflozin 5 or $15 \mathrm{mg}$ plus sitagliptin $100 \mathrm{mg}$ compared with either treatment as monotherapy (Table 2). After 26 weeks, coadministration of ertugliflozin + sitagliptin was significantly more effective than either treatment alone in reducing $\mathrm{HbA} 1 \mathrm{c}$ and FPG and increasing the number of patients achieving $\mathrm{HbA} 1 \mathrm{c}<7.0 \%$. Ertugliflozin $5 \mathrm{mg}$, ertugliflozin $15 \mathrm{mg}$, and sitagliptin $100 \mathrm{mg}$ showed a reduction from baseline in $\mathrm{HbA} 1 \mathrm{c}$ of $-1.0 \%,-1.1 \%$, and $-1.1 \%$, respectively ( $p$ is nonsignificant among the three groups); the addition of sitagliptin $100 \mathrm{mg}$ determined a further decrease in HbA1c (ertugliflozin $5 \mathrm{mg}+$ sitagliptin $100 \mathrm{mg}-1.5 \%$; ertugliflozin

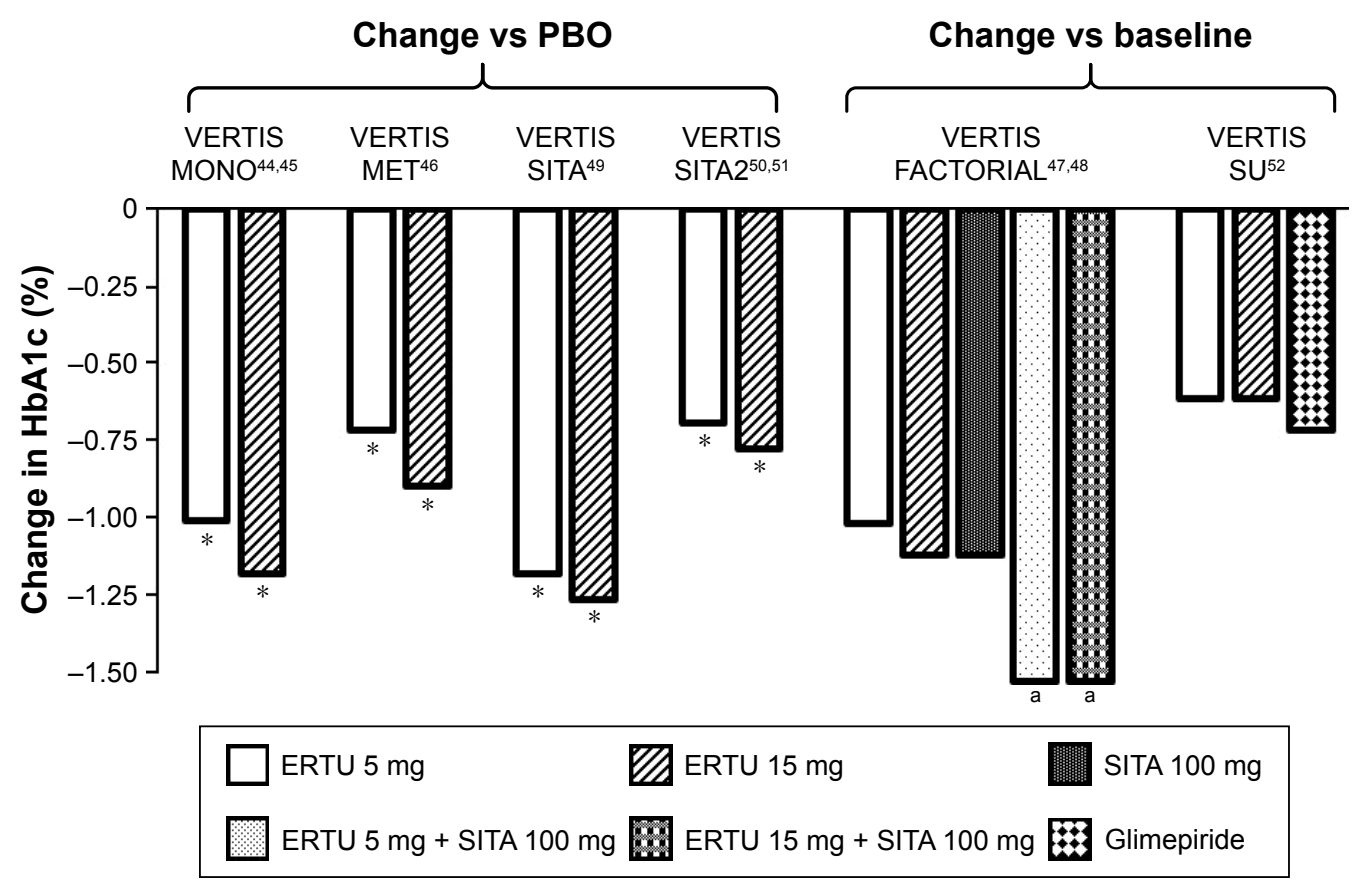

Figure 3 Mean change in $\mathrm{HbAlc}$.

Notes: ${ }^{*} p<0.001 .{ }^{a} p<0.004$ versus individual treatment.

Abbreviations: ERTU, ertugliflozin; HbAIc, glycosylated hemoglobin; SITA, sitagliptin; PBO, placebo. 
$15 \mathrm{mg}+$ sitagliptin $100 \mathrm{mg}-1.5 \%$; $p<0.004$ ) (Figure 3; Table S1).

Similar results were obtained for FPG in terms of reduction from baseline (ertugliflozin $5 \mathrm{mg}-35.7 \mathrm{mg} / \mathrm{dL}$; ertugliflozin $15 \mathrm{mg}-36.9 \mathrm{mg} / \mathrm{dL}$; sitagliptin $100 \mathrm{mg}-25.6 \mathrm{mg} / \mathrm{dL}$; ertugliflozin $5 \mathrm{mg}+$ sitagliptin $100 \mathrm{mg}-44 \mathrm{mg} / \mathrm{dL}$; ertugliflozin $15 \mathrm{mg}+$ sitagliptin $100 \mathrm{mg}-48.7 \mathrm{mg} / \mathrm{dL}$ ). Importantly, with sitagliptin $100 \mathrm{mg}$ and ertugliflozin coadministration, a greater proportion of patients achieved $\mathrm{HbA} 1 \mathrm{c}<7.0 \%$ (ertugliflozin $5 \mathrm{mg}+$ sitagliptin $100 \mathrm{mg}$ : 52.3\%; ertugliflozin $15 \mathrm{mg}+$ sitagliptin $100 \mathrm{mg}$ : 49.2\%; ertugliflozin $5 \mathrm{mg}$ : 26.4\%; ertugliflozin $15 \mathrm{mg}$ : $31.9 \%$; sitagliptin $100 \mathrm{mg}$ : $32.8 \%$ ). ${ }^{47}$ The treatment was continued in a double-blind 26-week extension phase, attaining an even greater decrease in HbA1c and FPG (Table S1). ${ }^{48}$

The VERTIS SITA trial investigated the efficacy of ertugliflozin in combination with sitagliptin in subjects with T2DM inadequately controlled with diet and exercise. Subjects were randomized 1:1:1 to take ertugliflozin $5 \mathrm{mg}+$ sitagliptin $100 \mathrm{mg}$, ertugliflozin $15 \mathrm{mg}+$ sitagliptin $100 \mathrm{mg}$ or placebo (Table 2). As expected, after 26 weeks, the two treatment groups showed a larger reduction from baseline in $\mathrm{HbA1c}$, which was significant in the pairwise comparison with placebo (ertugliflozin $5 \mathrm{mg}+$ sitagliptin $100 \mathrm{mg}-1.16 \%$, $p<0.001$; ertugliflozin $15 \mathrm{mg}+$ sitagliptin $100 \mathrm{mg}-1.24 \%$, $p<0.001$ ) (Figure 3, Table S1). There was also a meaningful reduction in FPG (ertugliflozin $5 \mathrm{mg}+$ sitagliptin $100 \mathrm{mg}$ : $-48.3 \mathrm{mg} / \mathrm{dL}$; ertugliflozin $15 \mathrm{mg}+$ sitagliptin $100 \mathrm{mg}$ : $-55.4 \mathrm{mg} / \mathrm{dL}$; placebo: $-9.3 \mathrm{mg} / \mathrm{dL}$ ) and 2-hour post-meal glucose PMG (ertugliflozin $5 \mathrm{mg}+$ sitagliptin $100 \mathrm{mg}$ : $-82.8 \mathrm{mg} / \mathrm{dL}$; ertugliflozin $15 \mathrm{mg}+$ sitagliptin $100 \mathrm{mg}$ : $-90 \mathrm{mg} / \mathrm{dL}$; placebo: $-20.4 \mathrm{mg} / \mathrm{dL}$ ). Furthermore, the respective comparison with placebo, for both FPG and 2-hour PMG, was significant $(p<0.001)$. The percentage of subjects achieving $\mathrm{HbA} 1 \mathrm{c}<7.0 \%$ was higher with ertugliflozin + sitagliptin compared to placebo (ertugliflozin $5 \mathrm{mg}+$ sitagliptin $100 \mathrm{mg}$ : 35.7\%; ertugliflozin $15 \mathrm{mg}+$ sitagliptin $100 \mathrm{mg}$ : $31.3 \%$; placebo: $8.3 \%$ ). ${ }^{49}$

VERTIS SITA2, another study in the VERTIS clinical development program, assessed the safety and efficacy of adding ertugliflozin 5 or $15 \mathrm{mg}$ compared with placebo to the dual combination of metformin and sitagliptin, after 26 weeks of treatment (Table 2). Blood glucose control after 26 weeks of treatment was more effective with ertugliflozin 5 and $15 \mathrm{mg}$ compared with placebo. In particular, the mean change in $\mathrm{HbA} 1 \mathrm{c}$ was greater with ertuginflozin $5 \mathrm{mg}(-0.68 \%$, $p<0.001)$ and $15 \mathrm{mg}(-0.76 \%, p<0.001)$ compared with placebo $(-0.1 \%)$. The same effects were observed for FPG
(5 mg -26.9 mg/dL; $25 \mathrm{mg}-33.1 \mathrm{mg} / \mathrm{dL} ; \mathrm{PBO}-1.8 \mathrm{mg} / \mathrm{dL}$ ) and a greater proportion of subjects treated with ertugliflozin 5 and $25 \mathrm{mg}$ reached the target of $\mathrm{HbAlc}<7.0 .^{50}$ The study extension at 52 weeks has shown similar results (Table S1). ${ }^{51}$

The VERTIS SU trial evaluated the efficacy and safety of once-daily ertugliflozin 15 or $5 \mathrm{mg}$ compared with glimepiride (initiated at $1 \mathrm{mg}$ and uptitrated to a maximum of 6 or $8 \mathrm{mg}$ /day) over 52 weeks, in patients with T2DM inadequately controlled with metformin. The primary endpoint was to assess non-inferiority in reducing $\mathrm{HbAlc}$. Ertugliflozin $15 \mathrm{mg}$ was non-inferior to glimepiride in reducing HbA1c (ertugliflozin $15 \mathrm{mg}$ vs glimepiride: 0.1 [ $-0.0 ; 0.2]$ $p<0.001)$ while non-inferiority could not be demonstrated for ertugliflozin $5 \mathrm{mg}(0.2[0.1 ; 0.3] p=\mathrm{ns}) .^{52}$

\section{Body weight}

As mentioned earlier, SGLT2 inhibition promotes significant energy loss through glycosuria, which causes weight loss. ${ }^{53}$ This is evident within 4 weeks of treatment but continues for up to 102 weeks in the longer duration trials..$^{54,55}$ In particular, reduction in body-fat mass accounts for $68 \%-90 \%$ of the weight loss induced by SGLT2is, as reported in several clinical trials. ${ }^{14,56-58}$

As with other gliflozins, ertugliflozin is also effective in reducing body weight, as proven in several randomized controlled trials, probably due to caloric loss and increased diuresis. ${ }^{14,59-61}$ After 12 weeks of ertugliflozin, at doses ranging from 1 to $25 \mathrm{mg}$, body weight decreased significantly in all treatment groups, compared with placebo and sitagliptin $100 \mathrm{mg} .{ }^{43}$

After 26 weeks of ertugliflozin monotherapy (5 and $15 \mathrm{mg}$ ), T2DM subjects, inadequately controlled by diet and exercise alone, achieved significant weight loss compared to placebo (ertugliflozin $5 \mathrm{mg}-1.76 \mathrm{~kg}, p<0.001$; ertugliflozin $15 \mathrm{mg}-2.16 \mathrm{~kg}, p<0.001)^{44}$ (Figure 4). Weight loss continued till week 52, after the active-controlled second phase of the study: at this point, the ertugliflozin $5 \mathrm{mg}$ group showed a $3.23 \mathrm{~kg}$ decrease in body weight and the ertugliflozin $15 \mathrm{mg}$ group a $3.38 \mathrm{~kg}$ decrease, compared with baseline values (Table S2) ${ }^{45}$

In the VERTIS MET trial, the addition of ertugliflozin 5 and $15 \mathrm{mg}$ to at least $1,500 \mathrm{mg}$ of metformin determined significant weight loss, compared to placebo (Figure 4). ${ }^{46}$

Coadministration of ertugliflozin 5 and $15 \mathrm{mg}$ and sitagliptin $100 \mathrm{mg}$ led to an effective decrease in body weight (ertugliflozin $5 \mathrm{mg}+$ sitagliptin $100 \mathrm{mg}:-2.5 \mathrm{~kg}, p<0.001$; ertugliflozin $15 \mathrm{mg}+$ sitagliptin $100 \mathrm{mg}:-2.9 \mathrm{~kg}, p<0.001$ ), 


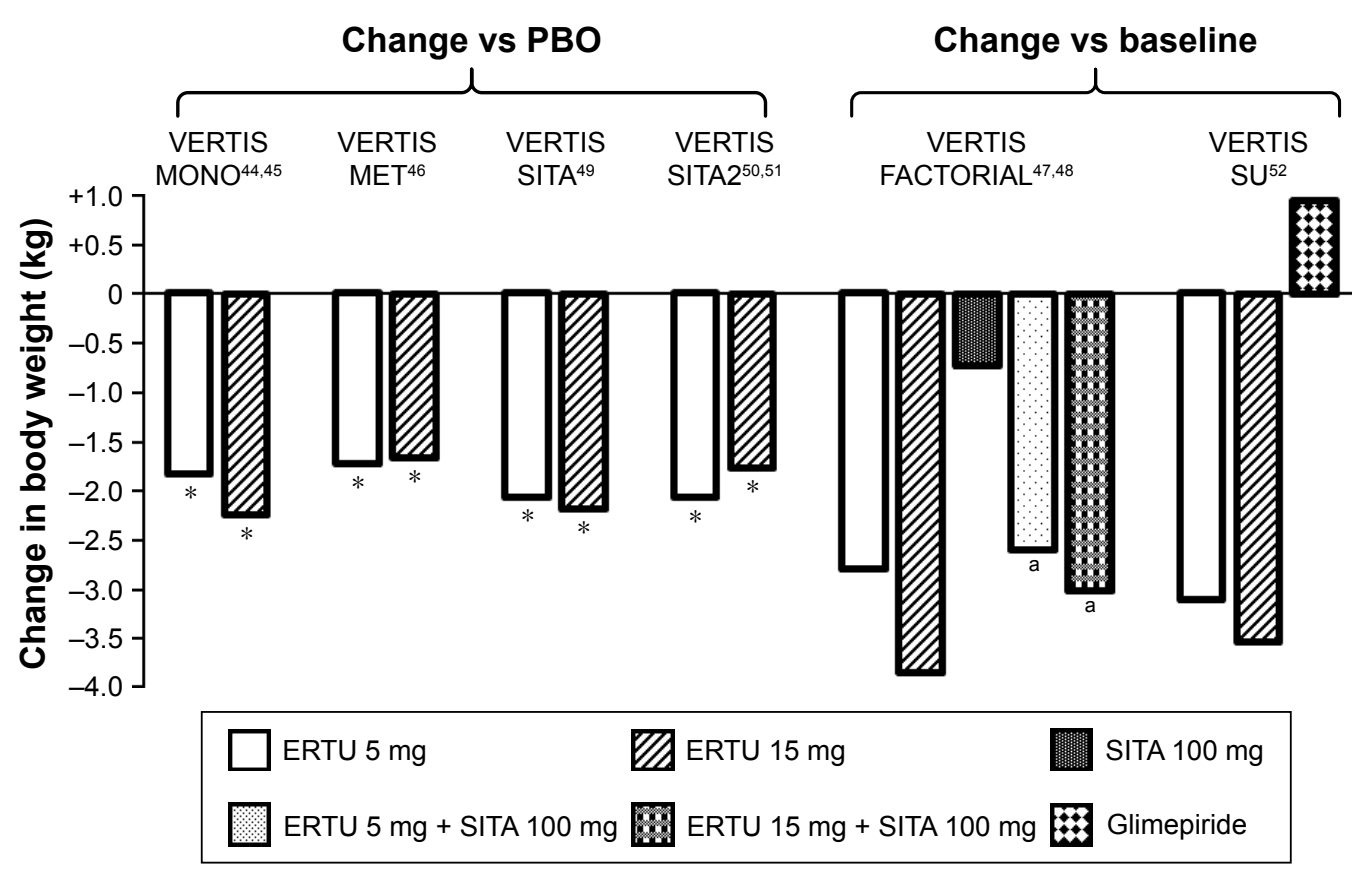

Figure 4 Mean change in body weight.

Notes: ${ }^{*} p<0.00$ I. ${ }^{a} p<0.005$ versus SITA.

Abbreviations: ERTU, ertugliflozin; SITA, sitagliptin; PBO, placebo.

compared to sitagliptin alone, which was not significant if compared to ertugliflozin 5 and $15 \mathrm{mg}$ alone (sitagliptin $100 \mathrm{mg}$ : $-0.7 \mathrm{~kg}$; ertugliflozin $5 \mathrm{mg}$ : $-2.7 \mathrm{~kg}$; ertugliflozin $15 \mathrm{mg}:-3.7 \mathrm{~kg}){ }^{47}$

A similar body weight reduction for each group was reached at week 52 (Table S2). ${ }^{48}$

The VERTIS SITA trial showed that ertugliflozin $5 \mathrm{mg}$ or ertugliflozin $15 \mathrm{mg}$ with sitagliptin combination therapy was effective in inducing weight loss, compared to placebo (ertugliflozin $5 \mathrm{mg}+$ sitagliptin $100 \mathrm{mg}:-2.0 \mathrm{~kg}, p<0.001$; ertugliflozin $15 \mathrm{mg}+$ sitagliptin $100 \mathrm{mg}:-3 \mathrm{~kg}, p<0.001$ ) after 26 weeks of treatment (Figure 4). ${ }^{49}$

Furthermore, the addition of ertugliflozin 5 or $15 \mathrm{mg}$ to metformin $1,500 \mathrm{mg}$ and sitagliptin $100 \mathrm{mg}$ determined considerable body weight reduction, compared with placebo (ertugliflozin $5 \mathrm{mg}:-2 \mathrm{~kg}, p<0.001$; ertugliflozin $15 \mathrm{mg}:-1.7 \mathrm{~kg}$, $p<0.001$ ), which persisted at week 52 (Figure 4; Table S2). ${ }^{50,51}$

As expected, in the VERTIS SU trial, both ertugliflozin 5 and $15 \mathrm{mg}$ induced a greater weight loss compared to glimepiride (ertugliflozin $5 \mathrm{mg}$ vs glimepiride: $-3.9 \mathrm{~kg}$ [-4.4; -3.4] nominal $p<0.001$; ertugliflozin $15 \mathrm{mg}$ vs glimepiride: $-4.3 \mathrm{~kg}[-4.8 ;-3.8] p<0.001){ }^{52}$

\section{Blood pressure}

As previously explained, SGLT2is play an important role in lowering both SBP and DBP. A Phase II dose-ranging study showed a decrease in SBP from baseline (placebo-corrected least squares mean) as early as week 4 with ertugliflozin $5 \mathrm{mg}(-2.59 \mathrm{mmHg}$; $p=0.087)$ and $10 \mathrm{mg}(-2.86 \mathrm{mmHg} ; p=0.068)$, which continued to be observed at week 12 with ertugliflozin $5-25 \mathrm{mg}$ /day (5 mg: $-3.48 \mathrm{mmHg}, p=0.056$; $10 \mathrm{mg}:-2.88 \mathrm{mmHg}, p=0.096$; $25 \mathrm{mg}$ : $-3.37 \mathrm{mmHg}, p=0.064){ }^{43}$

In the first-phase VERTIS MONO trial, the ertugliflozin $15 \mathrm{mg}$ versus placebo comparison for SBP was not significant, so the pre-specified hypothesis testing sequence was halted and testing of ertugliflozin $5 \mathrm{mg}$ versus placebo for SBP and for both ertugliflozin groups versus placebo for DBP was not performed. ${ }^{44}$ At week 52, however, a meaningful reduction was observed in SBP (ertugliflozin $5 \mathrm{mg}$ : $-3.27 \mathrm{mmHg}$; ertugliflozin $15 \mathrm{mg}$ : $-2.24 \mathrm{mmHg}$ ) rather than DBP (ertugliflozin $5 \mathrm{mg}$ : $-0.73 \mathrm{mmHg}$; ertugliflozin $15 \mathrm{mg}$ : $0.18 \mathrm{mmHg})^{45}$

However, results from other Phase III studies have shown significant reductions in SBP when ertugliflozin was added to metformin or metformin and sitagliptin (VERTIS FACTORIAL, VERTIS SITA, and VERTIS SITA2); therefore, like other SGLT2is, ertugliflozin is effective in reducing BP.

In the VERTIS SU trial, both 5 and $15 \mathrm{mg}$ ertugliflozin groups showed a greater reduction in SBP compared to glimepiride (ertugliflozin $5 \mathrm{mg}$ vs glimepiride: $-3.2 \mathrm{mmHg}$ [-4.7; -1.7] nominal $p<0.001$; ertugliflozin $15 \mathrm{mg}$ vs glimepiride: $-4.8 \mathrm{mmHg}[-6.3 ;-3.3]$ nominal $p<0.001) .{ }^{52}$ 


\section{Safety and tolerability}

\section{Adverse events}

SGLT2is seem to obtain clinical benefits without significant side effects or are at least well tolerated. ${ }^{62}$ The most commonly reported side effects are genital fungal infections (GFIs) and rare urinary tract infections (UTIs) triggered by the glycosuria. ${ }^{63}$

In a Phase II dose-ranging study, in T2DM patients inadequately controlled with metformin, ertugliflozin was generally well tolerated over the 12 -week treatment period. ${ }^{43}$ Serious adverse events (cellulitis, syncope, and acute myocardial infarction) have been recorded in pre-randomization and post-randomization phases of the study, even though none were considered treatment related. The most commonly reported adverse events (AEs) across all treatment groups were upper respiratory tract infections, diarrhea, UTIs, and GFIs. The latter two occurred in seven of the 328 subjects (two in placebo, two in ertugliflozin $1 \mathrm{mg}$, three in ertugliflozin $10 \mathrm{mg}$ group) and nine of the 328 randomized patients (one in placebo, one in ertugliflozin $5 \mathrm{mg}$, three in ertugliflozin $10 \mathrm{mg}$, and four in ertugliflozin $25 \mathrm{mg}$ ). No subjects receiving sitagliptin had signs/symptoms of UTI or GFI. Ten participants experienced hypoglycemia AEs during the study; five during the metformin run-in period and five during the treatment period (three in ertugliflozin $5 \mathrm{mg}$; one in $10 \mathrm{mg}$; one in $25 \mathrm{mg}$ ). None of these required external assistance. General frequency of AEs symptomatic of volume depletion (eg, dehydration, hypotension, and hypovolemia) was rare; four subjects reported dizziness (possible volume depletion AE).

The ertugliflozin safety profile is therefore similar to that of other SGLT2is. ${ }^{64}$ In conclusion, ertugliflozin was well tolerated in this population, with the majority of AEs being of mild or moderate intensity.

In a Phase III study (VERTIS MONO), the total incidence of AEs in ertugliflozin and placebo groups was similar (Table 3). Both the doses of ertugliflozin (5 and $15 \mathrm{mg}$ ) were generally safe and well tolerated during the study period (26 weeks). Genital mycotic infections in women occurred in $11(16.4 \%)$ and $14(22.6 \%)$ participants in the ertugliflozin 5 and $15 \mathrm{mg}$ groups, respectively, compared with four participants $(5.6 \%)$ in the placebo group ( $p=0.043$ and $p=0.005$ for ertugliflozin 5 and $15 \mathrm{mg}$, respectively, compared with placebo).

In men, genital mycotic infections occurred in three (3.4\%) and five $(5.6 \%)$ participants in the ertugliflozin 5 and $15 \mathrm{mg}$ groups, respectively, compared with $1(1.2 \%)$ in the placebo group. There were no serious genital mycotic

Table 3 Phase III completed clinical trials: adverse events

\begin{tabular}{|c|c|c|c|c|c|c|}
\hline \multirow[t]{2}{*}{ Study } & \multirow[t]{2}{*}{ Arms } & \multicolumn{5}{|c|}{ Adverse events } \\
\hline & & $\begin{array}{l}\text { GFI } \\
\text { (women) }\end{array}$ & $\begin{array}{l}\text { GFI } \\
\text { (men) }\end{array}$ & UTI & $\begin{array}{l}\text { Symptomatic } \\
\text { hypoglycemia }\end{array}$ & Hypovolemia \\
\hline VERTIS MONO ${ }^{44,45}$ & PBO/MET $(n=153)$ & $7(9.9)$ & $\mathrm{I}(\mathrm{I} .2)$ & $21(13.7)$ & $7(4.6)$ & $7(4.6)$ \\
\hline \multirow[t]{2}{*}{ (after 52 weeks) } & ERTU $5 \mathrm{mg}(\mathrm{n}=156)$ & $18(26.9)^{\mathrm{a}}$ & $3(3.4)$ & $17(10.9)$ & $2(1.3)$ & $3(1.9)$ \\
\hline & ERTU I5 mg $(n=152)$ & I8 (29) & $7(7.8)^{c}$ & $10(6.6)^{d}$ & $4(2.6)$ & $3(2.0)$ \\
\hline \multirow[t]{3}{*}{ VERTIS MET ${ }^{46}$} & PBO (n=209) & I (0.9) & $0(0.0)$ & $2(1.0)$ & $4(1.9)$ & $\mathrm{I}(0.5)$ \\
\hline & ERTU $5 \mathrm{mg}(\mathrm{n}=207)$ & $6(5.5)$ & $3(3.1)$ & $6(2.9)$ & $7(3.4)$ & $\mathrm{I}(0.5)$ \\
\hline & ERTU I5 mg $(n=205)$ & $7(6.3)^{\mathrm{e}}$ & $3(3.2)$ & $7(3.4)$ & $7(3.4)$ & $2(1.0)$ \\
\hline VERTIS & ERTU $5 \mathrm{mg}(\mathrm{n}=250)$ & - & - & - & 2.4 & 1.6 \\
\hline \multirow[t]{4}{*}{ FACTORIAL $47,48, *$} & ERTU I5 mg ( $\mathrm{n}=248)$ & - & - & - & - & 0.8 \\
\hline & SITA $100 \mathrm{mg}(\mathrm{n}=247)$ & - & - & - & - & 0 \\
\hline & ERTU $5 \mathrm{mg}+$ SITA $100 \mathrm{mg}(\mathrm{n}=243)$ & - & - & - & - & 0 \\
\hline & ERTU I5 mg + SITA $100 \mathrm{mg}(\mathrm{n}=244)$ & - & - & - & 4.9 & 0 \\
\hline \multirow[t]{3}{*}{ VERTIS SITA ${ }^{49, * *}$} & $\mathrm{PBO}(\mathrm{n}=97)$ & $2(5.0)$ & $0(0.0)$ & $5(5.2)$ & $\mathrm{I}(\mathrm{I} .0)$ & $\mathrm{I}(\mathrm{I} .0)$ \\
\hline & ERTU $5 \mathrm{mg}+$ SITA $100 \mathrm{mg}(\mathrm{n}=98)$ & $2(4.9)$ & $3(5.3)$ & $8(8.2)$ & $3(3.1)$ & $2(2.0)$ \\
\hline & ERTU I5 mg + SITA I00 mg (n=96) & $3(7.0)$ & I (I.9) & $3(3.1)$ & $3(3.1)$ & $2(2.1)$ \\
\hline VERTIS SITA2 $2^{50,51}$ & PBO $(n=153)$ & 1.9 & 0 & 2 & 2.6 & 0.7 \\
\hline \multirow[t]{2}{*}{ (after 26 weeks) } & ERTU 5 mg $(n=156)$ & 8 & 4.9 & 2.6 & 3.2 & 0.6 \\
\hline & ERTU I5 mg $(n=153)$ & 12.7 & 3.7 & 4.6 & 0.7 & 0 \\
\hline \multirow[t]{3}{*}{ VERTIS SU ${ }^{52}$} & ERTU 5 mg $(n=448)$ & $17(7.7)$ & $10(4.4)$ & $30(6.7)$ & $14(3.1)$ & $5(1.3)$ \\
\hline & ERTU I $5 \mathrm{mg}(\mathrm{n}=440)$ & $25(10.0)$ & $4(2.1)$ & $28(6.4)$ & $23(5.2)$ & $3(0.7)$ \\
\hline & Titrated glimepiride $(n=437)$ & $3(1.4)$ & $0(0)$ & $30(6.9)$ & 84 (19.2) & $3(0.7)$ \\
\hline
\end{tabular}

Notes: ${ }^{a} p=0.010$ vs PBO/MET; ${ }^{b} p=0.005$ vs PBO/MET; ${ }^{c} p=0.042$ vs PBO/MET; ${ }^{d} p=0.039$ PBO/MET; eincidence significantly higher $(p=0.032)$ versus $\mathrm{PBO}$. $*$ Empty cells $=$ incomplete data and/or see text. **All p-values for the comparison between ERTU 5/SITA 100 vs PBO and ERTU I5/ SITA 100 vs PBO are $\geq 0.05$.

Abbreviations: ERTU, ertugliflozin; SITA, sitagliptin; MET, metformin; PBO, placebo; GFI, genital fungal infection; UTI, urinary tract infection. 
infection AEs. In general, genital mycotic infections in women had a significantly higher incidence with ertugliflozin than in the placebo group. The incidence of genital mycotic infections was also higher in men in the ertugliflozin groups compared with placebo groups, but this difference was not significant.

The incidence of UTI in the ertugliflozin 5 and $15 \mathrm{mg}$ groups was $7.1 \%$ and $3.9 \%$, respectively, compared with $8.5 \%$ for placebo. One UTI AE led to discontinuation of the study medication in a man in the placebo group. There were no serious UTI AEs. The incidence of hypovolemia in the ertugliflozin 5 and $15 \mathrm{mg}$ groups was $1.3 \%$ and $2.0 \%$, respectively, compared with $3.9 \%$ in the placebo group.

Events associated with symptomatic hypoglycemia and documented hypoglycemia were unusual in both the ertugliflozin and placebo groups. The percentage of participants with symptomatic hypoglycemia AEs were placebo, 1.3\%; ertugliflozin $5 \mathrm{mg}, 1.3 \%$; and ertugliflozin $15 \mathrm{mg}, 2.6 \%$. Documented hypoglycemia, which included symptomatic and asymptomatic hypoglycemia, occurred in one participant $(0.7 \%)$ in the placebo group and four participants $(2.6 \%)$ in each of the ertugliflozin 5 and $15 \mathrm{mg}$ groups. Two participants in the ertugliflozin $15 \mathrm{mg}$ group experienced a severe hypoglycemia AE; one episode required non-professional assistance and one required professional assistance (Table 3 ). ${ }^{44}$

An increased incidence of genital mycotic infections was reported in the Phase III VERTIS MET study. Adverse events in women increased in the ertugliflozin $5 \mathrm{mg}$ group and were markedly higher in the ertugliflozin $15 \mathrm{mg}$ group compared to placebo ( $p=0.032$ ). The incidence in men was higher in both ertugliflozin groups versus placebo. The incidence of UTIs and symptomatic hypoglycemia AEs was greater in both ertugliflozin groups versus placebo. The incidence of hypovolemia was low and similar across all treatment groups. In conclusion, ertugliflozin was largely well tolerated but was correlated with a higher incidence of genital mycotic infections compared with placebo (Table 3). ${ }^{46}$

In the VERTIS FACTORIAL double-blind Phase III trial, the incidence of adverse events was identical across groups, except for higher rates of genital mycotic infections in groups treated with ertugliflozin vs sitagliptin alone (females, $4.9 \%-7.6 \%$ vs $1.1 \%$; males, $2.4 \%-4.7 \%$ vs $0 \%$, respectively).

UTI rates were higher with ertugliflozin alone (but not ertugliflozin + sitagliptin) vs sitagliptin alone (range: $3.2 \%$ [SITA] to $5.6 \%$ [ERTU $15 \mathrm{mg}$ ]). The incidence of symptomatic hypoglycemia was $2.4 \%$, in the group treated with ertugliflozin $5 \mathrm{mg}$ and $4.9 \%$ in the group treated with ertugliflozin
$15 \mathrm{mg}+$ sitagliptin. Hypovolemia AE rates were $1.6 \%$ and $0.8 \%$ in ertugliflozin 5 and $15 \mathrm{mg}$ groups, respectively, and $0 \%$ in all other groups (Table 3$).{ }^{47}$

After 52 weeks, the percentage of genital mycotic infections in the treatment groups with ertugliflozin + sitagliptin was similar to that observed in the treatment group with ertugliflozin alone and significantly higher than that observed in the group treated with sitagliptin alone $(p<0.05$, except ertugliflozin $5 \mathrm{mg}+$ sitagliptin in females).

Incidence of symptomatic hypoglycemia did not differ across groups but was higher in the group treated with ertugliflozin $15 \mathrm{mg}+$ sitagliptin. Incidence of UTIs and hypovolemia was comparable across groups. ${ }^{48}$

In the Phase III VERTIS SITA trial, the incidence of AEs was not meaningfully different across groups (all $p$-values for the comparison between Ertu 5/Sita 100 vs placebo and Ertu 15/Sita 100 versus placebo are $\geq 0.05$ ); no deaths were recorded during the study (Table 3 ). ${ }^{49}$

In the VERTIS SITA2 Phase III trial, after 26 weeks, the incidence of AEs was comparable among treatment groups, but a higher rate of genital mycotic infections was recorded with ertugliflozin 5 and $15 \mathrm{mg}$ (males: $4.9 \%$ and $3.7 \%$ vs no events with placebo; females: $8.0 \%$ and $12.7 \%$ vs $1.9 \%$ with placebo).

Incidence of UTI was similar in placebo and ertugliflozin $5 \mathrm{mg}$ groups $(2.0 \%$ and $2.6 \%)$ but higher in the ertugliflozin $15 \mathrm{mg}$ group (4.6\%).

Among groups, rates were similar for symptomatic hypoglycemia (placebo 2.6\%; ertugliflozin $5 \mathrm{mg}, 3.2 \%$; ertugliflozin $15 \mathrm{mg}, 0.7 \%$ ) and hypovolemia AEs (placebo $0.7 \%$; ertugliflozin $5 \mathrm{mg}, 0.6 \%$; ertugliflozin $15 \mathrm{mg}$, no events) (Table 3). ${ }^{50}$

After 52 weeks, rates of genital mycotic infections were higher in ertugliflozin treatment groups compared to placebo

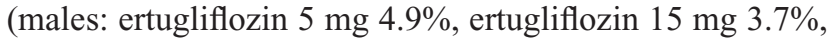
placebo $0 \%$; females: ertugliflozin $5 \mathrm{mg} 12.0 \%$, ertugliflozin

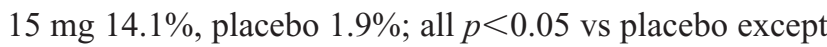
ertugliflozin $15 \mathrm{mg}$ males). The incidence of UTIs, symptomatic hypoglycemia and hypovolemia AEs did not differ significantly among groups. ${ }^{5}$

In the VERTIS SU trial, after 52 weeks, compared to glimepiride, the ertugliflozin 5 and $15 \mathrm{mg}$ treatment groups showed higher rates of genital mycotic infections (males: ertugliflozin $5 \mathrm{mg} 10$ [4.4], ertugliflozin $15 \mathrm{mg} 4$ [82.1], glimepiride 0 [0]), while no significant difference in UTIs and hypovolemia were observed among the three groups (Table 3). As expected, both ertugliflozin groups showed less symptomatic hypoglycemia than the glimepiride group 
(ertugliflozin $5 \mathrm{mg} 14$ [3.1]; ertugliflozin $15 \mathrm{mg} 23$ [5.2]; glimepiride 84 [19.2]).52

\section{Laboratory variables}

To date, few data have been collected on changes in lowdensity lipoprotein - high-density lipoprotein (LDL-HDL) cholesterol during treatment with SGLT2s. Previous studies observed a slight increment in LDL and HDL cholesterol, even though the mechanism remains unknown. ${ }^{3,64}$

In the VERTIS MONO Phase III study, mean baseline LDL cholesterol was $\sim 100 \mathrm{mg} / \mathrm{dL}$ in all treatment groups. At week 26, the LS mean placebo-adjusted percent change in LDL cholesterol from baseline was 4.05\% (95\% CI -2.82, $10.92)$ and $8.69 \%(95 \% \mathrm{CI} 1.75,15.63)$ for ertugliflozin 5 and $15 \mathrm{mg}$, respectively. Mean baseline HDL cholesterol level was $\sim 45 \mathrm{mg} / \mathrm{dL}$ for each treatment group. At week 26 , the LS mean placebo-adjusted percent change in HDL cholesterol from baseline was $4.70 \%$ (95\% CI $0.71,8.69)$ and $8.57 \%$ $(95 \%$ CI $4.55,12.59)$ for ertugliflozin 5 and $15 \mathrm{mg}$ groups, respectively. ${ }^{44}$

In the Phase III VERTIS MET study, at week 26, in both treatment groups with ertugliflozin $5 \mathrm{mg}$ or $15 \mathrm{mg}$, eGFR values were similar at baseline (mean [SD] change from baseline, $\mathrm{mL} / \mathrm{min} / 1.73 \mathrm{~m}^{2}$ : placebo 1.0 [10.7], ertugliflozin $5 \mathrm{mg} 0.3$ [12.0], ertugliflozin $15 \mathrm{mg} 0.2$ [14.8]). The placebo adjusted difference in LS mean $(95 \% \mathrm{CI})$ percent change from baseline to week 26 in LDL-C was $2.0(-6.0,10.0)$ for ertugliflozin $5 \mathrm{mg}$ and $2.6(-5.5,10.7)$ for ertugliflozin $15 \mathrm{mg}$. Respective values for HDL-C were $4.5(1.4,7.6)$ and $4.4(1.3,7.5){ }^{46}$

\section{Conclusion}

Ertugliflozin represents another valid SGLT2i for the treatment of T2DM. As with other gliflozins, its insulin-independent mechanism is effective in reducing $\mathrm{HbAlc}, \mathrm{BP}$, and body weight, both as monotherapy and in combination with other glucose-lowering agents. Individual variations in response to SGLT2is have been reported, partially attributable to genetic variations. ${ }^{65} \mathrm{~T} 2 \mathrm{DM}$ is a heterogeneous disease, and response to an antidiabetic medication, such as an SGLT2i, could vary considerably among individuals; therefore, identification of pharmacogenetic biomarkers to predict therapeutic response might be important to maximize benefits and minimize side effects in personalized medicine. ${ }^{66}$

As expected, the clinical benefits of ertugliflozin are obtained without significant side effects. Currently, clinical trials investigating the safety and efficacy of ertugliflozin in treating T1DM are still lacking. Despite the thrilling results obtained in SGLT2i clinical trials, in terms of not only glycemic control but also $\mathrm{CV}$ protection, one conundrum still awaits solution: will gliflozins change the natural history of diabetes? To date, not surprisingly, sequential add-on therapy results with ertugliflozin have shown a significant improvement in glucose metabolism. We still lack data from studies on head to head comparison of SGLT2i molecules, which might help to choose the right medication case by case. However, the possibility of having ertugliflozin in combination therapy with sitagliptin, the most prescribed DPP-4 inhibitor, is an undeniable advantage. In future, one challenge might be to study their effects as combined initial therapy in newly diagnosed T2DM, having durability as a primary outcome, that is, the ability to maintain adequate glucose control without the (usual) need to add further treatment. Gliflozins, in combination with a DPP-4 inhibitor and metformin, as initial therapy, could modify the natural history of diabetes and slow down its progression. ${ }^{67}$

\section{Acknowledgment}

We thank Serena Rotunno who provided editorial assistance in the preparation of this manuscript.

\section{Author contributions}

All authors participated in the conception and drafting of the manuscript and reviewed it for intellectual content. All authors contributed toward data analysis, drafting and critically revising the paper and agree to be accountable for all aspects of the work.

\section{Disclosure}

AG has received consultancy fees from Boehringer Ingelheim, MSD, Sanofi, Eli Lilly, Takeda, and Astra Zeneca. The sponsors were not directly involved in the design and conduct of the paper, the collection, management, analysis, and interpretation of the data, or the preparation, review, or approval of the manuscript. The authors report no other conflicts of interest in this work.

\section{References}

1. Gerich JE. Role of the kidney in normal glucose homeostasis and in the hyperglycaemia of diabetes mellitus: therapeutic implications. Diabet Med. 2010;27(2):136-142.

2. Jiang M, Steyger PS. An evaluation of US patent 2015065565 (A1) for a new class of SGLT2 inhibitors for treatment 1 of type II diabetes mellitus. Expert Opin Ther Pat. 2015;25(11):1349-1352.

3. DeFronzo RA, Norton L, Abdul-Ghani M. Renal, metabolic and cardiovascular considerations of SGLT2 inhibition. Nat Rev Nephrol. 2017;13(1): $11-26$.

4. Wright EM, Turk E. The sodium/glucose cotransport family SLC5. Pflugers Archiv. 2004;447(5):510-518.

5. Pajor AM, Wright EM. Cloning and functional expression of a mammalian $\mathrm{Na}+$ /nucleoside cotransporter. A member of the SGLT family. $J$ Biol Chem. 1992;267(6):3557-3560. 
6. DeFronzo RA, Davidson JA, Del Prato S. The role of the kidneys in glucose homeostasis: a new path towards normalizing glycaemia. Diabetes Obes Metab. 2012;14(1):5-14.

7. Lu Y, Griffen SC, Boulton DW, Leil TA. Use of systems pharmacology modeling to elucidate the operating characteristics of SGLT1 and SGLT2 in renal glucose reabsorption in humans. Front Pharmacol. 2014;5:274.

8. Wang XX, Levi J, Luo Y, et al. SGLT2 protein expression is increased in human diabetic nephropathy: SGLT2 protein inhibition decreases renal lipid accumulation, inflammation and the development of nephropathy in diabetic mice. J Biol Chem. 2017;292(13):5335-5348.

9. Solini A, Rossi C, Mazzanti CM, Proietti A, Koepsell H, Ferrannini E. Sodium-glucose co-transporter (SGLT)2 and SGLT1 renal expression in patients with type 2 diabetes. Diabetes Obes Metab. Epub 2017 Apr 17.

10. Giaccari A, Sorice G, Muscogiuri G. Glucose toxicity: the leading actor in the pathogenesis and clinical history of type 2 diabetes mechanisms and potentials for treatment. Nutr Metab Cardiovasc Dis. 2009; 19(5):365-377.

11. Robertson RP, Harmon J, Tran PO, Tanaka Y, Takahashi H. Glucose toxicity in beta-cells: type 2 diabetes, good radicals gone bad, and the glutathione connection. Diabetes. 2003;52(3):581-587.

12. Scheen AJ, Paquot N. Metabolic effects of SGLT-2 inhibitors beyond increased glucosuria: a review of the clinical evidence. Diabetes Metab. 2014;40(6 Suppl 1):S4-S11.

13. Majewski C, Bakris GL. Blood pressure reduction: an added benefit of sodium-glucose cotransporter 2 inhibitors in patients with type 2 diabetes. Diabetes Care. 2015;38(3):429-430.

14. Ferrannini G, Hach T, Crowe S, Sanghvi A, Hall KD, Ferrannini E. Energy balance after sodium-glucose cotransporter 2 inhibition. Diabetes Care. 2015;38(9):1730-1735.

15. Zinman B, Wanner C, Lachin JM, et al. Empagliflozin, cardiovascular outcomes, and mortality in type 2 diabetes. $N$ Engl J Med. 2015; 373(22):2117-2128.

16. Neal B, Perkovic V, Mahaffey KW, et al. Canagliflozin and cardiovascular and renal events in type 2 diabetes. $N$ Engl J Med. Epub 2017 Jun 12.

17. Ferrannini E, Mark M, Mayoux E. CV protection in the EMPA-REG OUTCOME trial: a "thrifty substrate" hypothesis. Diabetes Care 2016;39(7):1108-1114.

18. Lopaschuk GD, Verma S. Empagliflozin's fuel hypothesis: not so soon. Cell Metab. 2016;24(2):200-202.

19. Schnell O, Standl E, Catrinoiu D, et al. Report from the 2nd Cardiovascular Outcome Trial (CVOT) Summit of the Diabetes and Cardiovascular Disease (D\&CVD) EASD Study Group. Cardiovasc Diabetol. 2017;16(1):35.

20. Raz I. Guideline approach to therapy in patients with newly diagnosed type 2 diabetes. Diabetes Care. 2013;36(Suppl 2):S139-S144.

21. Inzucchi SE, Bergenstal RM, Buse JB, et al. Management of hyperglycemia in type 2 diabetes, 2015: a patient-centered approach: update to a position statement of the American Diabetes Association and the European Association for the Study of Diabetes. Diabetes Care. 2015;38(1):140-149.

22. Garber AJ, Abrahamson MJ, Barzilay JI, et al; American Association of Clinical Endocrinologists (AACE); American College of Endocrinology (ACE). Consensus statement by the American Association of Clinical Endocrinologists and American College of Endocrinology on the comprehensive type 2 diabetes management algorithm - 2016 executive summary. Endocr Pract. 2016;22(1):84-113.

23. Maliha G, Townsend RR. SGLT2 inhibitors: their potential reduction in blood pressure. J Am Soc Hypertens. 2015;9(1):48-53.

24. Baker WL, Smyth LR, Riche DM, Bourret EM, Chamberlin KW, White WB. Effects of sodium-glucose co-transporter 2 inhibitors on blood pressure: a systematic review and meta-analysis. J Am Soc Hypertens. 2014;8(4):262.e269-275.e269.

25. Mosley JF 2nd, Smith L, Everton E, Fellner C. Sodium-glucose linked transporter 2 (SGLT2) inhibitors in the management of type-2 diabetes: a drug class overview. P T. 2015;40(7):451-462.
26. Miller ER 3rd, Appel LJ. High prevalence but uncertain clinical significance of orthostatic hypotension without symptoms. Circulation. 2014;130(20):1772-1774.

27. Sha S, Polidori D, Heise T, et al. Effect of the sodium glucose co transporter 2 inhibitor canagliflozin on plasma volume in patients with type 2 diabetes mellitus. Diabetes Obes Metab. 2014;16(11): $1087-1095$

28. Tikkanen I, Narko K, Zeller C, et al. Empagliflozin reduces blood pressure in patients with type 2 diabetes and hypertension. Diabetes Care. 2015;38(3):420-428.

29. Liu XY, Zhang N, Chen R, Zhao JG, Yu P. Efficacy and safety of sodium-glucose cotransporter 2 inhibitors in type 2 diabetes: a metaanalysis of randomized controlled trials for 1 to 2 years. $J$ Diabetes Complications. 2015;29:1295-1303.

30. Cherney DZ, Perkins BA, Soleymanlou N, et al. Sodium glucose cotransport-2 inhibition and intrarenal RAS activity in people with type 1 diabetes. Kidney Int. 2014;86:1057-1058.

31. Kobori H, Nangaku M, Navar LG, et al. The intrarenal renin-angiotensin system: from physiology to the pathobiology of hypertension and kidney disease. Pharmacol Rev. 2007;59:251-287.

32. Yoshimoto T, Furuki T, Kobori H, et al. Effects of sodium-glucose cotransporter 2 inhibitors on urinary excretion of intact and total angiotensinogen in patients with type 2 diabetes. J Investig Med. Epub 2017 Jun 8.

33. Mascitti V, Maurer TS, Robinson RP, et al. Discovery of a clinical candidate from the structurally unique dioxa-bicyclo[3.2.1] octane class of sodium-dependent glucose cotransporter 2 inhibitors. J Med Chem. 2011;54(8):2952-2960.

34. Grempler R, Thomas L, Eckhardt M, et al. Empagliflozin, a novel selective sodium glucose cotransporter-2 (SGLT-2) inhibitor: characterisation and comparison with other SGLT-2 inhibitors. Diabetes Obes Metab. 2012;14(1):83-90

35. Zambrowicz B, Freiman J, Brown PM, et al. LX4211, a dual SGLT1/ SGLT2 inhibitor, improved glycemic control in patients with type 2 diabetes in a randomized, placebo-controlled trial. Clin Pharmacol Ther. 2012;92(2):158-169.

36. Lapuerta P, Zambrowicz B, Strumph P, Sands A. Development of sotagliflozin, a dual sodium-dependent glucose transporter $1 / 2$ inhibitor. Diabetes Vasc Dis Res. 2015;12(2):101-110.

37. Castaneda F, Burse A, Boland W, Kinne RK. Thioglycosides as inhibitors of hSGLT1 and hSGLT2: potential therapeutic agents for the control of hyperglycemia in diabetes. Int J Med Sci. 2007;4(3):131-139.

38. Dash RP, Babu RJ, Srinivas NR. Comparative pharmacokinetics of three SGLT-2 inhibitors sergliflozin, remogliflozin and ertugliflozin: an overview. Xenobiotica. 2016:1-12.

39. Kalgutkar AS, Tugnait M, Zhu T, et al. Preclinical species and human disposition of PF-04971729, a selective inhibitor of the sodiumdependent glucose cotransporter 2 and clinical candidate for the treatment of type 2 diabetes mellitus. Drug Metab Dispos. 2011;39(9): 1609-1619.

40. Miao Z, Nucci G, Amin N, et al. Pharmacokinetics, metabolism, and excretion of the antidiabetic agent ertugliflozin (PF-04971729) in healthy male subjects. Drug Metab Dispos. 2013;41(2):445-456.

41. Kumar V, Sahasrabudhe V, Matschke K, et al. Lack of a pharmacokinetic interaction between ertugliflozin and sitagliptin or metformin in healthy subjects. Poster presented at: ASCPT 2016 Annual Meeting of the American Society for Clinical Pharmacology and Therapeutics; March 12; 2016; San Diego, CA.

42. Sahasrabudhe V, Terra SG, Fountaine RJ, et al. The effect of renal impairment on the pharmacokinetics and pharmacodynamics of ertugliflozin in subjects with type 2 diabetes mellitus. Poster presented at: EASD 2015 51st European Association for the Study of Diabetes; September 14; 2015; Stockholm, Sweden.

43. Amin NB, Wang X, Jain SM, Lee DS, Nucci G, Rusnak JM. Doseranging efficacy and safety study of ertugliflozin, a sodium-glucose cotransporter 2 inhibitor, in patients with type 2 diabetes on a background of metformin. Diabetes Obes Metab. 2015;17(6):591-598. 
44. Terra SG, Focht K, Davies M, et al. Phase III, efficacy and safety study of ertugliflozin monotherapy in people with type 2 diabetes mellitus inadequately controlled with diet and exercise alone. Diabetes Obes Metab. 2017;19(5):721-728.

45. Aronson R, Goldman A, Frias J, et al. Long-term efficacy and safety of ertugliflozin monotherapy in patients with inadequately controlled T2DM despite diet and exercise: the 52-week VERTIS MONO study. Poster presented at: ADA 2017; June 8; 2017; San Diego, CA.

46. Rosenstock J, Frias J, Pall D, et al. Effect of ertugliflozin on glycemic control, body weight, blood pressure (BP), and bone mineral density (BMD) in T2DM inadequately controlled with metformin monotherapy: VERTIS MET Trial. Poster presented at: ADA 2017; June 8; 2017; San Diego, CA.

47. Pratley R, Eldor R, Golm G, et al. Safety and efficacy of ertugliflozin plus sitagliptin versus either treatment alone in subjects with type 2 diabetes inadequately controlled with metformin: the VERTIS FACTORIAL trial. Poster presented at: EASD 2016 52nd European Association for the Study of Diabetes; September 15; 2016; Munich, Germany.

48. Pratley R, Raji A, Eldor R, et al. Safety and efficacy of ertugliflozin plus sitagliptin vs. either treatment alone after 52 weeks in subjects with T2DM inadequately controlled on metformin: VERTIS FACTORIAL trial extension. Oral presentation at: ADA 2017; June 9; 2017; San Diego, CA.

49. Lauring B, Miller SS, Krumins T, et al. Safety and efficacy of ertugliflozin in combination with sitagliptin in subjects with T2DM inadequately controlled on diet and exercise: the VERTIS SITA Trial. Poster presented at: ADA 2017; June 8; 2017; San Diego, CA.

50. Lauring B, Eldor R, Liu J, et al. Efficacy and safety of ertugliflozin in subjects with type 2 diabetes mellitus inadequately controlled on the dual combination of metformin and sitagliptin: the VERTIS SITA2 trial. Poster presented at: EASD 2016 52nd European Association for the Study of Diabetes; September 15; 2016; Munich, Germany.

51. Liu J, Eldor R, Dagogo-Jack S, et al. Safety and efficacy of ertugliflozin after 52 weeks in subjects with T2DM inadequately controlled on metformin and sitagliptin: results from the extension phase of the VERTIS SITA2 Trial. Oral presentation at: ADA 2017; June 9; 2017; San Diego, CA.

52. Hollander P, Liu J, Hill J, et al. Safety and efficacy of ertugliflozin compared to glimepiride in patients with type 2 diabetes inadequately controlled on metformin: the VERTIS SU trial. Poster presentation at: EASD 2017; Lisbon, Portugal.

53. Rajeev SP, Cuthbertson DJ, Wilding JP. Energy balance and metabolic changes with sodium-glucose co-transporter 2 inhibition. Diabetes Obes Metab. 2016;18(2):125-134.

54. List JF, Woo V, Morales E, Tang W, Fiedorek FT. Sodium-glucose cotransport inhibition with dapagliflozin in type 2 diabetes. Diabetes Care. 2009;32(4):650-657.
55. Bolinder J, Ljunggren O, Johansson L, et al. Dapagliflozin maintains glycaemic control while reducing weight and body fat mass over 2 years in patients with type 2 diabetes mellitus inadequately controlled on metformin. Diabetes Obes Metab. 2014;16(2):159-169.

56. Yang XP, Lai D, Zhong XY, Shen HP, Huang YL. Efficacy and safety of canagliflozin in subjects with type 2 diabetes: systematic review and meta-analysis. Eur J Clin Pharmacol. 2014;70(10):1149-1158.

57. Zhang M, Zhang L, Wu B, Song H, An Z, Li S. Dapagliflozin treatment for type 2 diabetes: a systematic review and meta-analysis of randomized controlled trials. Diabetes Metabol Res Rev. 2014;30(3): 204-221.

58. Liakos A, Karagiannis T, Athanasiadou E, et al. Efficacy and safety of empagliflozin for type 2 diabetes: a systematic review and metaanalysis. Diabetes Obes Metab. 2014;16(10):984-993.

59. Cefalu WT, Leiter LA, Yoon KH, et al. Efficacy and safety of canagliflozin versus glimepiride in patients with type 2 diabetes inadequately controlled with metformin (CANTATA-SU): 52 week results from a randomised, double-blind, phase 3 non-inferiority trial. Lancet. 2013; 382(9896):941-950.

60. Rosenstock J, Vico M, Wei L, Salsali A, List JF. Effects of dapagliflozin, an SGLT2 inhibitor, on $\mathrm{HbA}(1 \mathrm{c})$, body weight, and hypoglycemia risk in patients with type 2 diabetes inadequately controlled on pioglitazone monotherapy. Diabetes Care. 2012;35(7):1473-1478.

61. Lavalle-Gonzalez FJ, Januszewicz A, Davidson J, et al. Efficacy and safety of canagliflozin compared with placebo and sitagliptin in patients with type 2 diabetes on background metformin monotherapy: a randomised trial. Diabetologia. 2013;56(12):2582-2592.

62. Chao EC, Henry RR. SGLT2 inhibition - a novel strategy for diabetes treatment. Nat Rev Drug Discov. 2010;9(7):551-559.

63. Liu J, Li L, Li S, et al. Effects of SGLT2 inhibitors on UTIs and genital infections in type 2 diabetes mellitus: a systematic review and metaanalysis. Sci Rep. 2017;7(1):2824.

64. Inzucchi SE, Zinman B, Wanner C, et al. SGLT-2 inhibitors and cardiovascular risk: proposed pathways and review of ongoing outcome trials. Diabetes Vasc Dis Res. 2015;12(2):90-100.

65. Dawed AY, Zhou K, Pearson ER. Pharmacogenetics in type 2 diabetes: influence on response to oral hypoglycemic agents. Pharmgenom Pers Med. 2016;9:17-29.

66. Lyssenko V, Bianchi C, Del Prato S. Personalized therapy by phenotype and genotype. Diabetes Care. 2016;39(Suppl 2):S127-S136.

67. Abdul-Ghani MA, Puckett C, Triplitt C, et al. Initial combination therapy with metformin, pioglitazone and exenatide is more effective than sequential add-on therapy in subjects with new-onset diabetes. Results from the Efficacy and Durability of Initial Combination Therapy for Type 2 Diabetes (EDICT): a randomized trial. Diabetes Obes Metab. $2015 ; 17(3): 268-275$. 


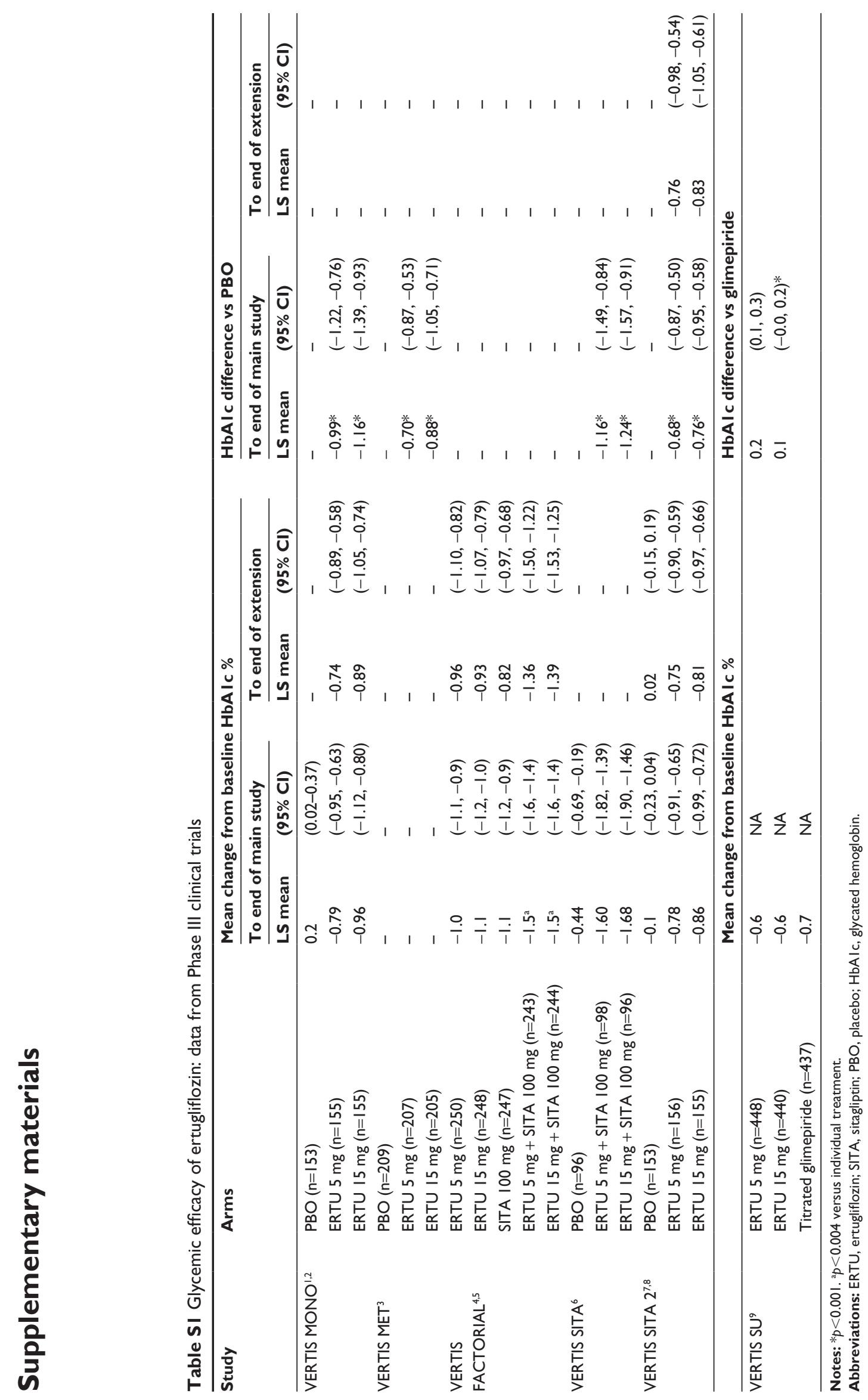




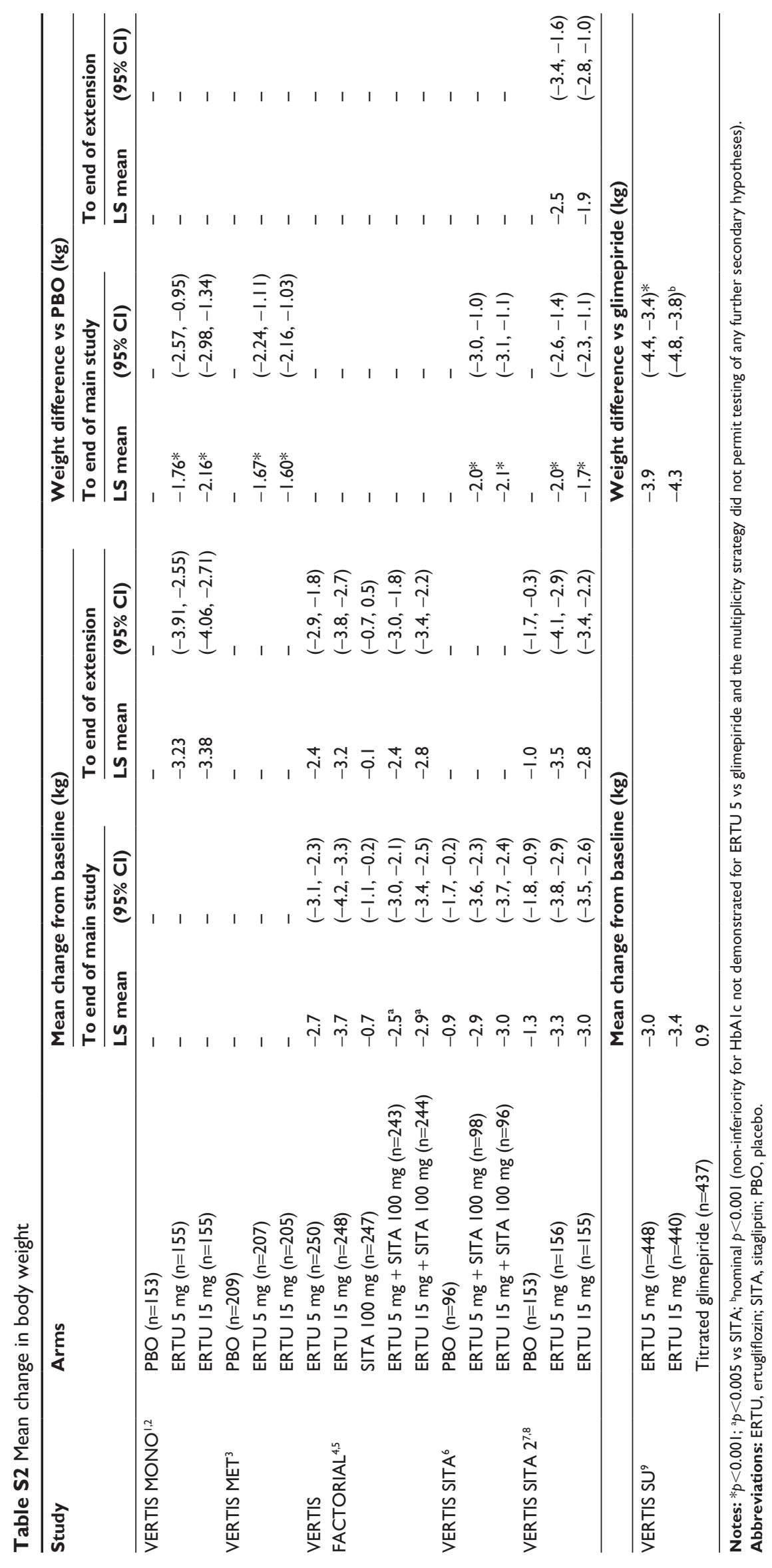




\section{References}

1. Terra SG, Focht K, Davies M, et al. Phase III, efficacy and safety study of ertugliflozin monotherapy in people with type 2 diabetes mellitus inadequately controlled with diet and exercise alone. Diabetes Obes Metab. 2017;19(5):721-728.

2. Aronson R, Goldman A, Frias J, et al. Long-term efficacy and safety of ertugliflozin monotherapy in patients with inadequately controlled T2DM despite diet and exercise: the 52-week VERTIS MONO study. Poster presented at: ADA 2017; June 8; 2017; San Diego, CA.

3. Rosenstock J, Frias J, Pall D, et al. Effect of ertugliflozin on glycemic control, body weight, blood pressure (BP), and bone mineral density (BMD) in T2DM inadequately controlled with metformin monotherapy: VERTIS MET Trial. Poster presented at: ADA 2017; June 8; 2017; San Diego, CA.

4. Pratley R, Eldor R, Golm G, et al. Safety and efficacy of ertugliflozin plus sitagliptin versus either treatment alone in subjects with type 2 diabetes inadequately controlled with metformin: the VERTIS FACTORIAL trial. Poster presented at: EASD 2016 52nd European Association for the Study of Diabetes; September 15; 2016; Munich, Germany.

5. Pratley R, Raji A, Eldor R, et al. Safety and efficacy of ertugliflozin plus sitagliptin vs. either treatment alone after 52 weeks in subjects with T2DM inadequately controlled on metformin: VERTIS FACTORIAL trial extension. Oral presentation at: ADA 2017; June 9; 2017; San Diego, CA.
6. Lauring B, Miller SS, Krumins T, et al. Safety and efficacy of ertugliflozin in combination with sitagliptin in subjects with T2DM inadequately controlled on diet and exercise: the VERTIS SITA Trial. Poster presented at: ADA 2017; June 8; 2017; San Diego, CA

7. Lauring B, Eldor R, Liu J, et al. Efficacy and safety of ertugliflozin in subjects with type 2 diabetes mellitus inadequately controlled on the dual combination of metformin and sitagliptin: the VERTIS SITA2 trial. Poster presented at: EASD 2016 52nd European Association for the Study of Diabetes; September 15; 2016; Munich, Germany.

8. Liu J, Eldor R, Dagogo-Jack S, et al. Safety and efficacy of ertugliflozin after 52 weeks in subjects with T2DM inadequately controlled on metformin and sitagliptin: results from the extension phase of the VERTIS SITA2 Trial. Oral presentation at: ADA 2017; June 9; 2017; San Diego, CA.

9. Hollander P, Liu J, Hill J, et al. Safety and efficacy of ertugliflozin compared to glimepiride in patients with type 2 diabetes inadequately controlled on metformin: the VERTIS SU trial. Poster presentation at: EASD 2017; Lisbon, Portugal.

\section{Publish your work in this journal}

Drug Design, Development and Therapy is an international, peerreviewed open-access journal that spans the spectrum of drug design and development through to clinical applications. Clinical outcomes, patient safety, and programs for the development and effective, safe, and sustained use of medicines are the features of the journal, which has also been accepted for indexing on PubMed Central. The manuscript management system is completely online and includes a very quick and fair peer-review system, which is all easy to use. Visit http://www.dovepress.com/testimonials.php to read real quotes from published authors.

Submit your manuscript here: http://www.dovepress.com/drug-design-development-and-therapy-journal 